\title{
L-glutamine Schiff base copper complex as a proteasome inhibitor and an apoptosis inducer in human cancer cells
}

\author{
YAN XIAO $^{1,2}$, CAIFENG BI $^{1}$, YUHUA FAN ${ }^{1}$, CINDY CUI $^{2}$, XIA ZHANG $^{1,2}$ and Q. PING DOU ${ }^{2}$ \\ ${ }^{1}$ Key Laboratory of Marine Chemistry Theory and Technology, Ministry of Education, College of Chemistry and \\ Chemical Engineering, Ocean University of China, Qingdao, P.R. China; ${ }^{2}$ The Prevention Program, Barbara Ann Karmanos \\ Cancer Institute, and Department of Pathology, School of Medicine, Wayne State University, Detroit, MI, USA
}

Received June 10, 2008; Accepted July 24, 2008

\section{DOI: 10.3892/ijo_00000096}

\begin{abstract}
Interest in the use of metallic compounds for cancer treatment has been increasing since the discovery of cisplatin. Clinical studies suggest the use of proteasome inhibitors as potential novel anticancer agents. L-glutamine is the most abundant free amino acid in the body, and has been shown to play a regulatory role in several cellular processes, including metabolism, degradation, redox potential and cellular integrity. Although glutamine is reported to play a role in the regulation of apoptosis, the effect of glutamine copper complex on tumor cells and the involved molecular mechanism have not been investigated. Here, for the first time, we report that a newly synthesized L-glutamine-containing copper complex has proteasome-inhibitory activity in human breast cancer and leukemia cells. The inhibition of the tumor proteasomal activity results in the accumulation of ubiquitinated proteins and ubiquitinated form of IкB- $\alpha$, a natural proteasome substrate, followed by induction of apoptosis. Furthermore, this glutamine Schiff base copper complex selectively inhibits the proteasomal activity and induces cell death in cultured breast cancer cells, but not normal, immortalized breast cells. Our data suggest that glutamine Schiff base copper complexes have a potential use for to be used in cancer treatment and prevention.
\end{abstract}

\section{Introduction}

Recent developments in chemotherapy are increasingly relying on apoptosis. Apoptosis is an evolutionarily conserved form of cell suicide. If a cell is unable to undergo apoptosis, due to mutation or biochemical inhibition, it could continue

Correspondence to: Dr Caifeng Bi, Key Laboratory of Marine Chemistry Theory and Technology, Ministry of Education, College of Chemistry and Chemical Engineering, Ocean University of China, Songling Road, Qingdao, Shandong 266100, P.R. China

E-mail: bcfeng@ouc.edu.cn

Dr Q. Ping Dou, The Prevention Program, Barbara Ann Karmanos Cancer Institute, and Department of Patho-logy, School of Medicine, Wayne State University, 540.1 HWCRC, 4100 John R Road, Detroit, MI 48201, USA

E-mail: doup@karmanos.org

Key words: L-glutamine, Schiff base, proteasome, apoptosis, tumor cell death dividing and facilitating tumor growth (1-3). Apoptosis has been shown to occur when cells are damaged beyond repair, infected with a virus, or undergoing stress conditions such as starvation, DNA damage or toxic chemicals $(1,2)$. Morphologically, the process of apoptosis is characterized by cellular condensation, nuclear fragmentation, and engulfment or phagocytosis by neighboring cells (3). It has been reported that proteasome inhibitors are potent apoptosis inducers when used in multiple cancer and transformed cell lines (4-6), and have potential use as novel anticancer agents $(7,8)$.

The induction of protein degradation is facilitated by two independent pathways: lysosome-mediated and ubiquitin/ proteasome-mediated pathways $(8,9)$. The latter is known as to degrade many endogenous proteins. The proteasome is a massive multicatalytic protease responsible for degrading a large number of cellular proteins. In order to be degraded by the proteasome, these target proteins are first tagged with ubiquitin, which can then target the substrate protein to the $26 \mathrm{~S}$ proteasome for destruction. The $20 \mathrm{~S}$ proteasome, the core of $26 \mathrm{~S}$ proteasome complex, contains at least three distinct catalytic activities including the chymotrypsin-like activity (10). Several studies have shown that inhibition of the proteasomal chymotrypsin-like activity resulted in the accumulation of several target proteins (i.e., IкB- $\alpha$ ) and induction of apoptosis in various types of tumor cells $(7,10)$.

The interest in metal-based anticancer drugs has increased since the development of cisplatin as one of the anticancer drugs (11). Since toxicity and other serious clinical problems were observed in the use of cisplatin (12), the search for other metals and ligands that might produce more specific anticancer effects is ongoing. Our laboratory has reported that metallic compounds, such as gallium, organic Schiff base copper and gold complexes, can inhibit the tumor cellular proteasome and induce apoptosis (13-15). Glutamine has been shown to regulate the expression of many genes related to metabolism, signal transduction, cell defense and repair, and to activate intracellular signaling pathways (16-18). The function of glutamine goes beyond that of a simple metabolic fuel or protein precursor as previously assumed. Evidence has accumulated that glutamine influences apoptosis-related cellular mechanisms in cancer cells.

Vanillin is a plant-derived natural product and has been used as food flavoring agent (19). O-vanillin, a positional isomer of vanillin, has been shown to be able to scavenge 
1,1-diphenyl-2-picrylhydrazyl (DPPH) radical, with potency greater than vanillin (19). In this study, we used a synthetic L-glutamine-o-vanillin (GV) as a copper-binding ligand to synthesize its copper complex, GVC (Fig. 1). We show, for the first time, that the GVC inhibits the cell proliferation of human breast cancer MDA-MB-231 cells. Furthermore, GVC has proteasome-inhibitory and apoptosis-inducing activities when tested in cultured human leukemic Jurkat $\mathrm{T}$ cells and human breast cancer MDA-MB-231 and MCF DCIS.com cells, but not normal, immortalized MCF 10A breast cells.

\section{Materials and methods}

Materials. Bisbenzimide, Hoechst no. 33258 stain, 3-[4,5dimethyltiazol-2-yl]-2.5-diphenyl-tetrazolium bromide (MTT), DMSO, and other chemicals were purchased from Sigma-Aldrich. RPMI-1640, DMEM/F-12, penicillin, and streptomycin were purchased from Invitrogen. Purified rabbit 20S proteasome and fluorogenic peptide substrate Suc-LLVY-AMC (for the proteasomal chymotrypsin-like) was from Calbiochem (San Diego, CA). Mouse monoclonal antibody against human poly (ADP-ribose) polymerase (PARP) was purchased from BD Biosciences Pharmingen (San Diego, CA). Mouse monoclonal antibody against ubiquitin (P4D1), goat polyclonal antibodies against actin (C-11) and IкB- $\alpha$ (C15), and secondary antibodies were from Santa Cruz Biotechnology, Inc.

Cell cultures and whole cell extract preparation. MDA-MB231 human breast cancer cells were obtained from American Type Culture Collection (Manassas, VA) and grown in DMEM/F-12 supplemented with $10 \%$ fetal bovine serum, $100 \mathrm{U} / \mathrm{ml}$ penicillin, and $100 \mu \mathrm{g} / \mathrm{ml}$ streptomycin. Human Jurkat T cells were cultured in RPMI-1640 medium, supplemented with $10 \%$ fetal bovine serum, $100 \mathrm{U} / \mathrm{ml}$ penicillin, and $100 \mu \mathrm{g} / \mathrm{ml}$ streptomycin. MCF 10A (normal, derived from benign human breast tissue) and MCF 10DCIS.com (human malignant breast cells) cells were cultured as previously described (20). All cells were maintained at $37^{\circ} \mathrm{C}$ and $5 \%$ $\mathrm{CO}_{2}$. A whole cell extract was prepared as described previously (21). Briefly, cells were harvested, washed with PBS and homogenized in a lysis buffer $(50 \mathrm{mM}$ Tris- $\mathrm{HCl}, \mathrm{pH} 7.5$, $150 \mathrm{mM} \mathrm{NaCl}, 0.5 \% \mathrm{NP}-40,0.5 \mathrm{mM}$ phenylmethylsulfonyl fluoride, and $0.5 \mathrm{mM}$ dithiothreitol) for $30 \mathrm{~min}$ at $4^{\circ} \mathrm{C}$. Afterwards, the lysates were centrifuged at $12,000 \mathrm{~g}$ for $12 \mathrm{~min}$ at $4^{\circ} \mathrm{C}$ and the supernatants collected as whole-cell extracts.

Inhibition of the proteasomal chymotrypsin-like activity in cell extracts. Whole cells extracts (5 $\mu \mathrm{g})$ of treated MDA-MB-231, MCF 10A and MCF 10DCIS.com cells were incubated for $2 \mathrm{~h}$ at $37^{\circ} \mathrm{C}$ in $100 \mu \mathrm{l}$ of assay buffer (50 mM Tris- $\left.\mathrm{HCl}, \mathrm{pH} 7.5\right)$, respectively, with $10 \mu \mathrm{mol} / 1$ fluorogenic peptide substrate Suc-LLVY-AMC for the proteasomal chymotrypsin-like activity. After incubation, production of hydrolyzed AMC groups was measured with a Wallac Victor 3 Multiabel Counter with an excitation filter of $365 \mathrm{~nm}$ and emission filter of $460 \mathrm{~nm}$. Changes in fluorescence were calculated against DMSO treated control.

Cellular and nuclear morphology analysis. A Zeiss (Thornwood, NY, USA) Axiovert 25 microscope was used for all<smiles>COC(=O)C(CCC(N)=O)N=Cc1cccc(OC)c1O</smiles>

\section{L-glutamine-o-vanillin (GV)}

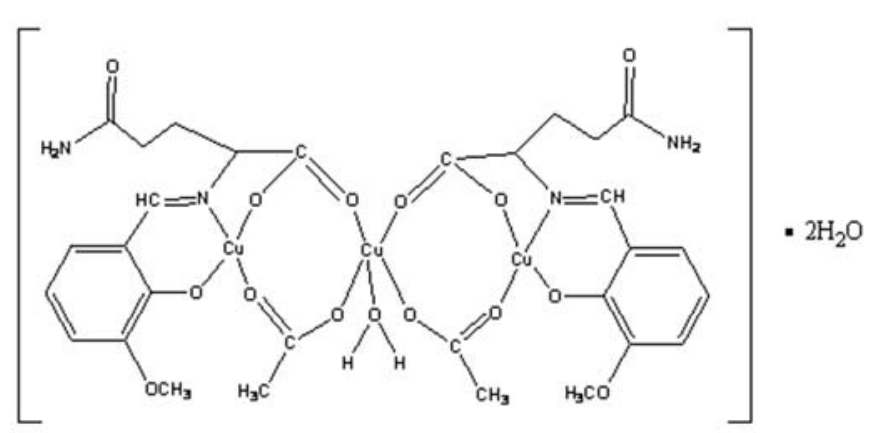

\section{L-glutamine-o-vanillin-copper (GVC)}

Figure 1. The chemical structures of GV and GVC.

microscopic imaging with phase contrast for cellular morphology or fluorescence for nuclear morphology with Hoechst staining, as previously described (22).

Cell proliferation assay. MDA-MB-231 cells were seeded in triplicate in a 96-well plate and grown until 70-80\% confluence, followed by treatment with indicated agents for $24 \mathrm{~h}$. Then, the 3-(4,5-dimethylthiazol-2-yl)-2,5-diphenyltetrazolium bromide assay was perfomed as described (23).

Trypan blue assay. The trypan blue dye exclusion assay was performed by mixing $20 \mu \mathrm{l}$ of Jurket T cells suspension treated with different concentration of GVC with $20 \mu \mathrm{l}$ of $0.4 \%$ trypan blue dye before injecting into a hemocytometer and counting. The number of cells that absorbed the dye and those that exclude the dye were counted, from which the percentage of nonviable cell number to total cell number was calculated.

Western blot analysis. The cell extracts were separated by SDS-PAGE and transferred to a nitrocellulose membrane. Western blot analysis was done using specific antibodies against ubquitin, IкB- $\alpha$, PARP and actin, following by visualization with the enhanced chemiluminescence reagent.

\section{Results}

GVC inhibits proliferation of human breast cancer MDA$M B-231$ cells. Our previous study that copper complexes are able to inhibit the chymotrypsin-like activity of the proteasome (23) suggests that several amino acids located in the proteasome 35 subunit might function as natural copper-binding ligands. In the current study, we first investigated the effect of copper complexes of amino acid L-glutamine on tumor cell growth. We used L-glutamine to react with o-vanillin to produce copper-binding ligand, L-glutamine-o-vanillin (GV) 


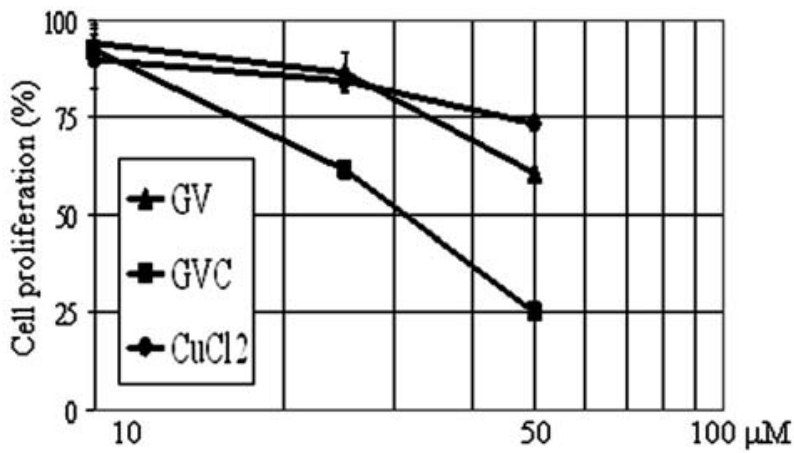

Figure 2. MTT assay of MDA-MB-231 cells treated with GV, GVC and $\mathrm{CuCl}_{2}$. MDA-MB-231 cells were treated with each indicated compound for $24 \mathrm{~h}$ at various concentrations as indicated. After $24 \mathrm{~h}$, the medium was removed, and the cells were treated with MTT solution, as described in Materials and methods.

(Fig. 1). We then synthesized the corresponding copper complex (Fig. 1). The synthetic processes of GV and GVC will be published elsewhere.

We then investigated the antiproliferative potency of this amino acid-copper complex. MDA-MB-231 breast cancer cells were plated into a 96-well plate and treated with GVC, $\mathrm{GV}$ or $\mathrm{CuCl}_{2}$ at various concentrations for $24 \mathrm{~h}$, followed by
MTT assay. Cells treated with DMSO were used as control. We found that GVC inhibited cellular proliferation in a concentration-dependent manner, causing $\sim 75 \%$ inhibition of cell growth at $50 \mu \mathrm{M}$ (Fig. 2). In contrast, the ligand GV at $50 \mu \mathrm{M}$ only induced $\sim 40 \%$ inhibition and copper chloride alone had little effect (Fig. 2). Therefore, we chose GVC for further studies.

GVC inhibits the proteasomal activity and induces apoptosis in MDA-MB-231 breast cancer cells in a concentrationdependent manner. We found that GVC was able to inhibit the chymotrypsin-like activity of a purified rabbit $20 \mathrm{~S}$ proteasome with potency lower than $\mathrm{CuCl}_{2}$ (data not shown). To test whether GVC is able to inhibit tumor cellular proteasome activity, MDA-MB-231 breast cancer cells were treated with various concentrations $(10-50 \mu \mathrm{M})$ of $\mathrm{GVC}, \mathrm{GV}$ and $\mathrm{CuCl}_{2}$ (as controls) for $24 \mathrm{~h}$. After each treatment, proteins were extracted and used for measurement of proteasome activity by decreasing levels of cellular proteasomal chymotrypsinlike activity, accumulation of ubiquitinated proteins and proteasome target protein IкB- $\alpha$. We found that cellular proteasomal chymotrypsin activity in MDA-MB-231 cells treated with GVC was significantly inhibited in a concentration-dependent manner: GVC at 25 and $40 \mu \mathrm{M}$ caused 65 and $80 \%$ inhibition, respectively (Fig. 3A). Consistently,
A

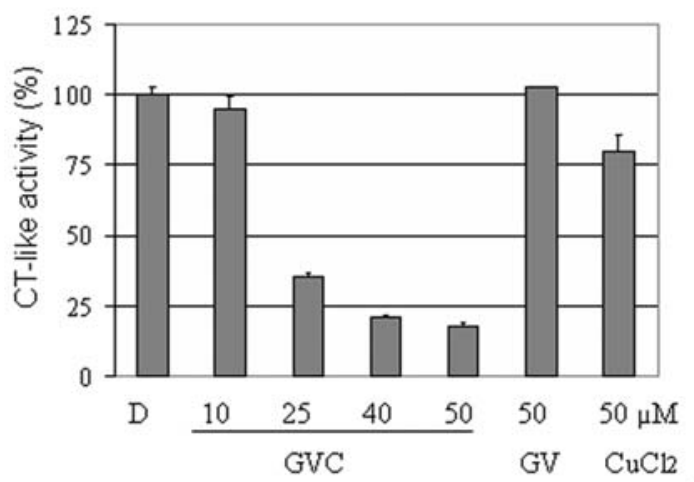

$\mathrm{C}$
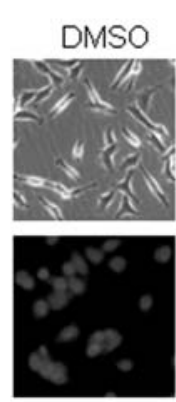

GVC
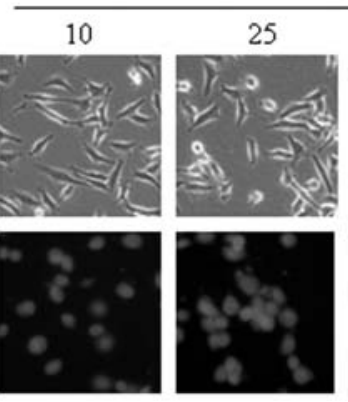

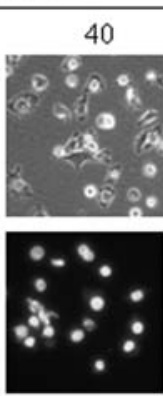

B
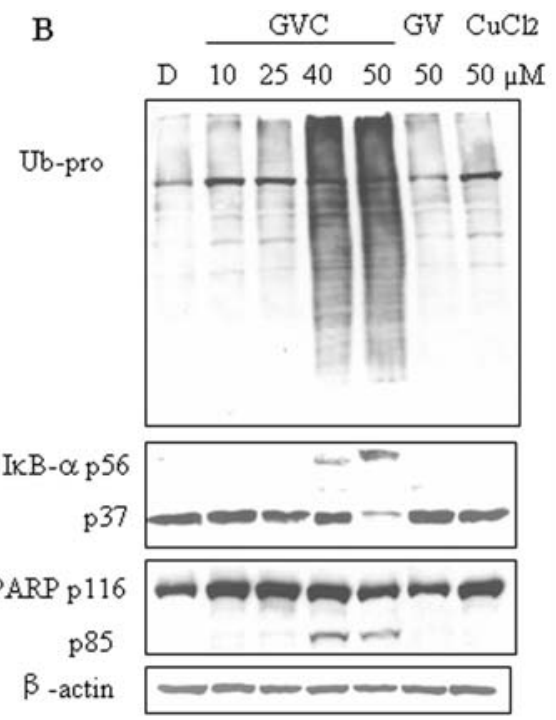

$\beta$-actin

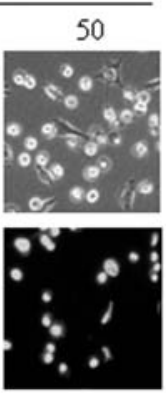

GV

$\mathrm{CuCl}_{2}$

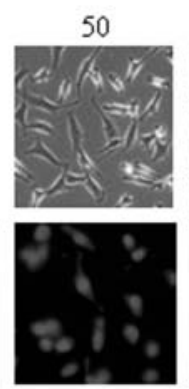

$50 \mu \mathrm{M}$

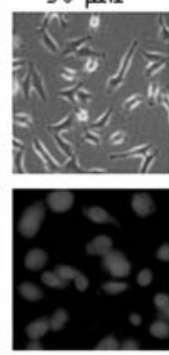

Figure 3. Dosage-effects of GVC on MDA-MB-231 cells. MDA-MB-231 cells were treated with DMSO (D) or different concentration of GVC, GV and CuCl 2 . (as controls) for $24 \mathrm{~h}$. (A) The inhibition of the proteasomal chymotrypsin-like activity. (B) Accumulation of ubiquitinated proteins (Ub-Prs) and Ub-IkB- $\alpha$ protein (p56), and the cleavage of PARP. Molecular weight of intact PARP is $116 \mathrm{kDa}$ and the cleaved PARP fragment is $85 \mathrm{kDa}$. B-actin was used as a loading control. (C) Cellular and nuclear apoptotic morphology changes. Upper, cellular morphologic changes (spherical and detached cells). Lower, apoptotic nuclear changes shown after Hoechst 33258 staining (punctuated, granular, and brighter nuclei). 
A

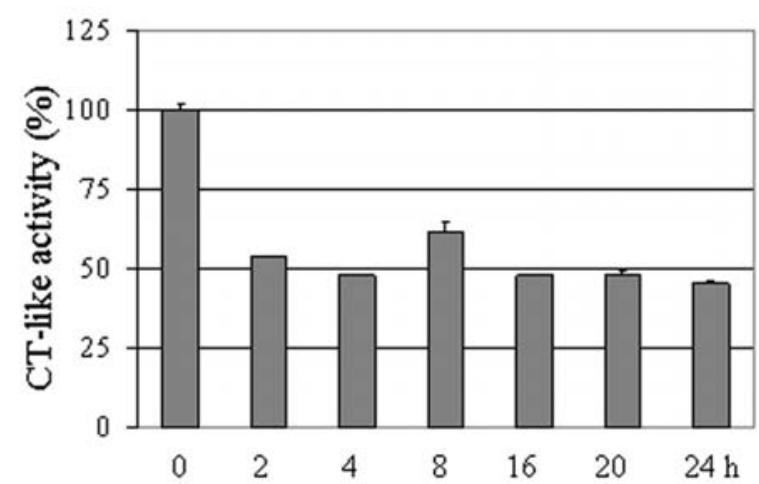

$\mathrm{C}$
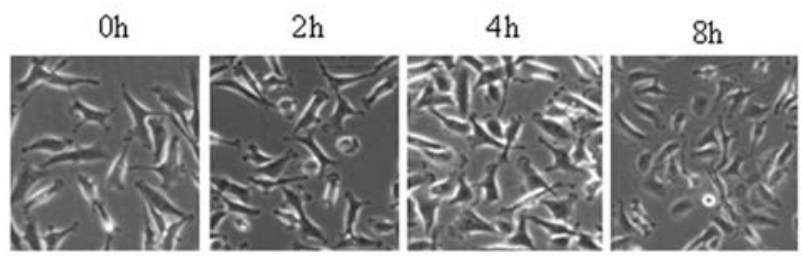

B $\begin{array}{llllllll}0 & 2 & 4 & 8 & 16 & 20 & 24 \mathrm{~h}\end{array}$
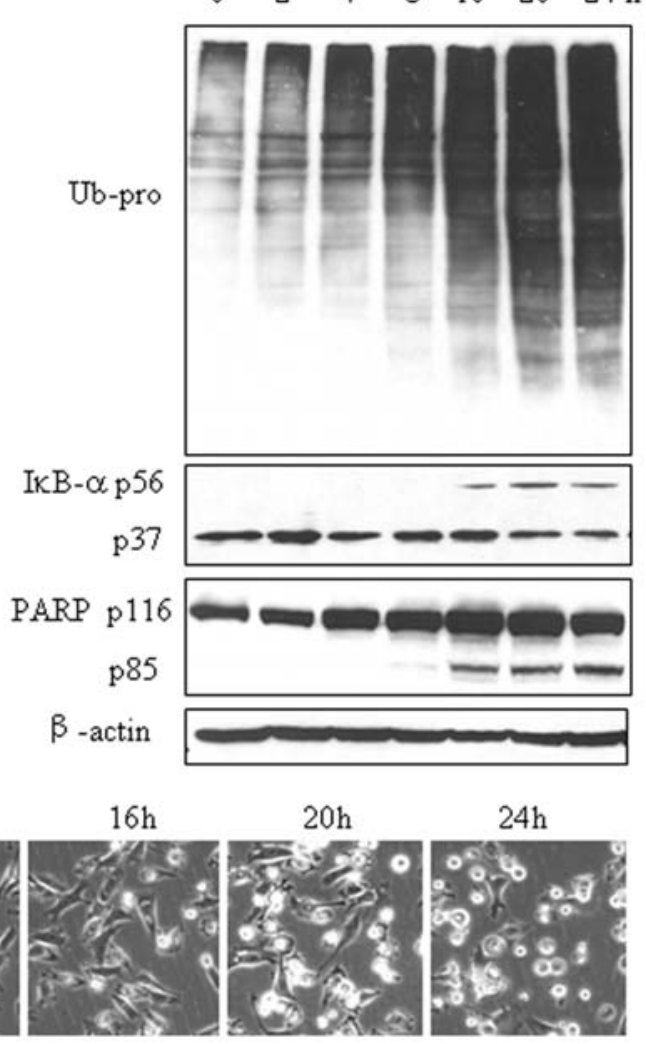

Figure 4. Kinetic studies on proteasome inhibition and apoptosis induction by GVC in MDA-MB-231 cells. MDA-MB-231 cells were exposed to $40 \mu \mathrm{M}$ GVC for the indicated times. (A) The inhibition of the proteasomal chymotrypsin-like activity. (B) Western blot assay using specific antibodies to ubiquitin, IkB- $\alpha$, PARP and $\beta$-actin. Molecular weight of IкB- $\alpha$ is $37 \mathrm{kDa}$ and ubiquitinated $\mathrm{I} \kappa \mathrm{B}-\alpha$ is $56 \mathrm{kDa}$. $\beta$-actin was used as a loading control. (C) The apoptotic morphologic changes.

levels of ubiquitinated proteins were accumulated in MDAMB-231 cells treated with GVC in a concentration-dependent manner (Fig. 3B). In contrast, both ligand $\mathrm{GV}$ and $\mathrm{CuCl}_{2}$ alone at the highest concentration $(50 \mu \mathrm{M})$ tested had little to no effect (Fig. 3A and B).

We have reported a ubiquitinated form of the well known proteasome target IкB- $\alpha$ protein with molecular weight of $\sim 56 \mathrm{kDa}$ (24-26). A similar ubiquitinated form of ІкB- $\alpha$ protein was observed in the cells treated with 40 and $50 \mu \mathrm{M}$ of $\mathrm{GVC}$, but not $\mathrm{GV}$ and $\mathrm{CuCl}_{2}$ (Fig. 3B). These results support the conclusion that $\mathrm{GVC}$ inhibits the cellular proteasome activity in intact MDA-MB-231 breast cancer cells.

It has been shown that inhibition of tumor cellular proteasome activity is associated with apoptosis induction (4-7). To explore whether GVC has apoptosis-inducing activity, both morphologic changes and apoptosis-associated PARP cleavage were studied. Changes in cellular apoptotic morphology (fragmentation and condensation cells and characteristic apoptotic blebbing) were observed only in the cells treated with GVC at 40 and $50 \mu \mathrm{M}$, but not $\mathrm{GV}$ or $\mathrm{CuCl}_{2}$ (Fig. 3C, upper). Consistent with apoptosis induction, we observed the production of apoptotic nuclei in the cells treated with GVC at 40 and $50 \mu \mathrm{M}$ after Hoechst staining (Fig. 3C, lower). Furthermore, treatment with GVC at 40 and $50 \mu \mathrm{M}$ caused the generation of PARP cleavage fragment p85 (Fig. 3B). These effects were not seen in the cells treated with either $\mathrm{GV}$ or $\mathrm{CuCl}_{2}$ (Fig. 3C). Therefore, GVC induces proteasome inhibition and apoptosis in breast cancer cells in a concentration-dependent manner.

Proteasome inhibition by GVC occurs prior to apoptosis in treated breast cancer cells. If inhibition of the proteasome by $\mathrm{GVC}$ is responsible for MDA-MB-231 breast cancer cell apoptosis, we should observe inhibition of proteasomal activity prior to cell death. To test this idea, MDA-MB-231 breast cancer cells were treated with $40 \mu \mathrm{M}$ of GVC for indicated time-points, followed by the measurement of proteasome inhibition and apoptosis. The proteasomal chymotrypsin-like activity was found to be inhibited by $\sim 45 \%$ after the first $2 \mathrm{~h}$ of treatment (Fig. 4A), which was associated with accumulated level of ubiquitinated proteins (Fig. 4B). Proteasome inhibition and accumulation of ubiquitinated proteins were observed during the time course of treatment (Fig. 4A and B). Also the ubiquitinated form of I $\mathrm{BB}-\alpha(56 \mathrm{kDa})$ was detected after GVC treatment (Fig. 4B). Importantly, apoptosis-specific PARP cleavage was not observed until $16 \mathrm{~h}$ of treatment (Fig. 4B). Consistently, cellular apoptotic morphologic changes (Fig. 4C) were also observed after $16 \mathrm{~h}$. These results clearly show that the proteasome inhibition induced by GVC occurred before apoptosis induction, suggesting that proteasome inhibition by GVC triggers tumor cell apoptosis.

Effect of GVC in human leukemic Jurkat T cells. To test whether GVC is also able to kill other human cancer cells, 
A

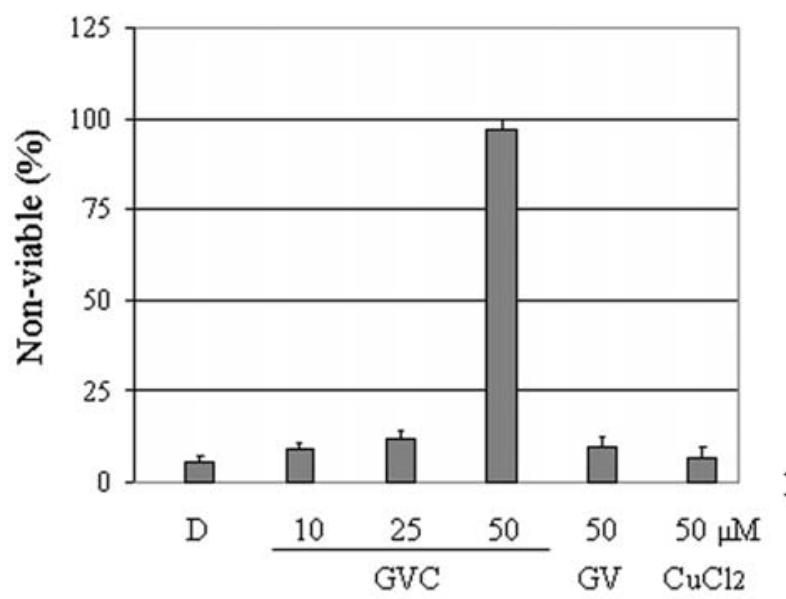

B

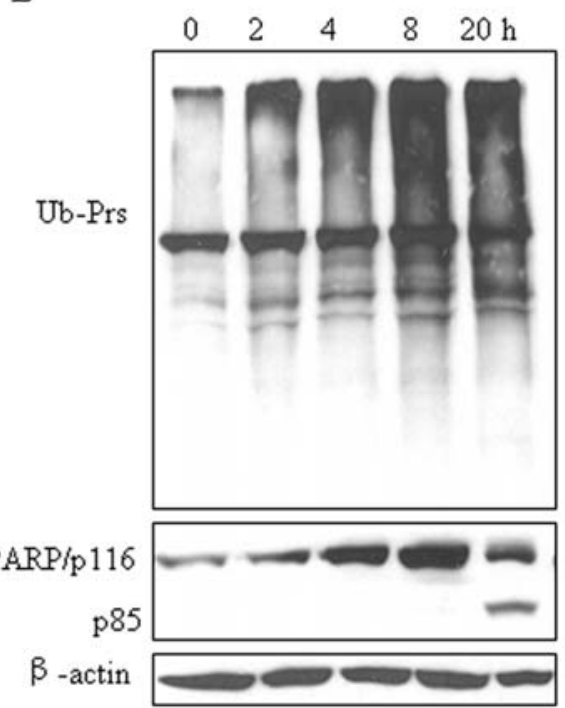

8

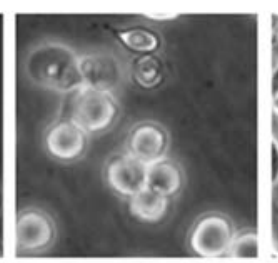

$20 \mathrm{~h}$

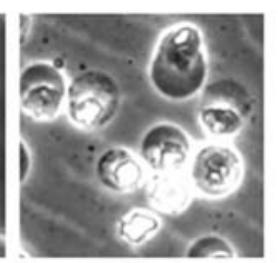

Figure 5. Dosage and kinetics of GVC in Jurkat T cells. (A) Jurkat T cells were treated with the solvent DMSO (D) or various concentrations of GVC or $50 \mu \mathrm{M}$ of $\mathrm{GV}$ and $\mathrm{CuCl}_{2}$. alone for $24 \mathrm{~h}$, followed by trypan blue dye exclusion assay. The data represented are the mean number of dead cells over total cell population \pm SD after treatment. (B) Jurkat T cells were treated with the $50 \mu \mathrm{M}$ GVC for the indicated times, followed by measuring accumulation of ubiquitinated proteins and cleavage of PARP. ß-actin was used as a loading control. (C) Apoptotic morphologic changes.

human leukemic Jurkat $\mathrm{T}$ cells were treated with various concentrations $(10-50 \mu \mathrm{M})$ of $\mathrm{GVC}$ or $50 \mu \mathrm{M}$ of $\mathrm{GV}$ and $\mathrm{CuCl}_{2}$ alone (as controls) for $24 \mathrm{~h}$, followed by trypan blue dye exclusion assay to examine cell death. Treatment with $50 \mu \mathrm{M}$ of GVC induced $>90 \%$ cell death, while either $\mathrm{GV}$ or $\mathrm{CuCl}_{2}$ at the same concentration had no effect (Fig. 5A). We then examined whether the GVC effect on leukemia cell death is time-dependent. In this experiment, accumulation of ubiquitinated proteins appeared as early as $2 \mathrm{~h}$, while PARP cleavage was observed after 20-h treatment (Fig. 5B). Morphologically, apoptotic changes were observed after 8 to 20-h treatment (Fig. 5C). These results support the notion that the apoptosis induced by GVC occurred after the proteasome inhibition.

The non-toxic effect of the GVC in normal, immortalized breast cells. The ability to induce apoptosis in tumor, but not normal, cells is an important criterion for novel anticancer drugs $(8,9)$. To determine whether GVC could inhibit the proteasome activity and induce apoptosis selectively in breast cancer over normal cells, we used a pair of normal and malignant breast cell lines, MCF 10A and MCF 10DCIS.com. MCF 10A cells are normal, immortalized breast cells, whereas MCF 10DCIS.com cells are malignant, which were derived from MCF 10A cells (20). Both MCF 10A and MCF 10DCIS.com cell lines were treated with $40 \mu \mathrm{M}$ of GVC, $\mathrm{GV}, \mathrm{CuCl}_{2}$, or DMSO for $48 \mathrm{~h}$, followed by measurement of proteasome inhibition and apoptosis. We found that GVC caused $\sim 50 \%$ inhibition of the proteasomal chymotrypsinlike activity in breast malignant MCF 10DCIS.com cells (Fig. 6A). In contrast, GVC did not inhibit the proteasomal activity in non-transformed MCF 10A cells (Fig. 6A). Treatment with $\mathrm{CuCl}_{2}$ induced some proteasome inhibition in both MCF 10DCIS.com and MCF 10A cells while other treatments had little or no effects on either cell line (Fig. 6A).

To determine whether failure of GVC to inhibit the proteasome activity in MCF 10A cells is associated with lack of apoptosis induction in these normal, immortalized breast cells, apoptosis-associated cellular and nuclear morphologic changes were then measured in the aliquots of both cell lines in the same experiment. The MCF 10DCIS.com cells treated with the GVC, but not others, were detached (Fig. 6B) and also showed the apoptotic nuclear changes (Fig. 6C). However, the normal, immortalized MCF $10 \mathrm{~A}$ cells treated with the GVC or others showed no cell death-related detachment or apoptotic nuclear changes (Fig. 6B and C). Out data strongly suggest that GVC could inhibit the proteasomal activity and induce apoptosis selectively in human malignant cells but not in normal, immortalized breast cells.

\section{Discussion}

Some of the important apoptosis-inducing antineoplastic drugs are those with a metallic center, such as cisplatin, which has 


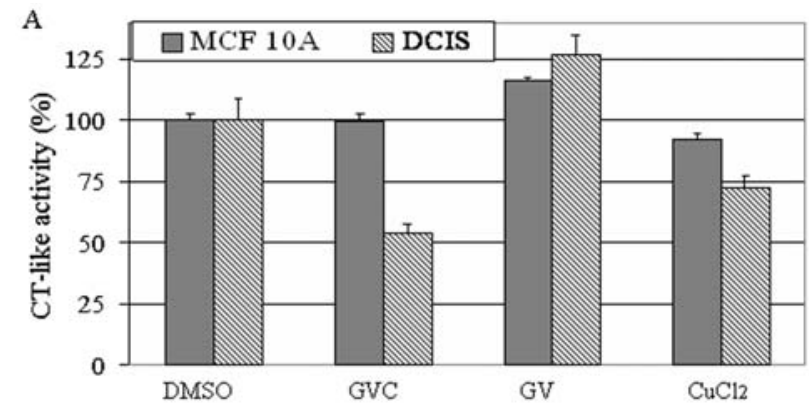

B

DMSO

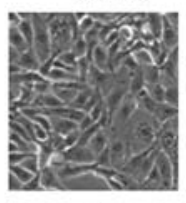

GVC

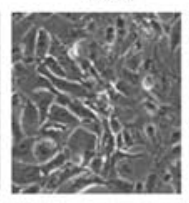

GV

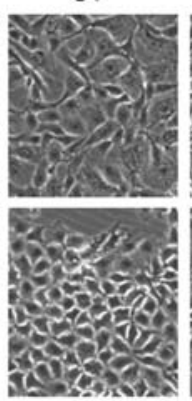

$\mathrm{CuCl} 2$
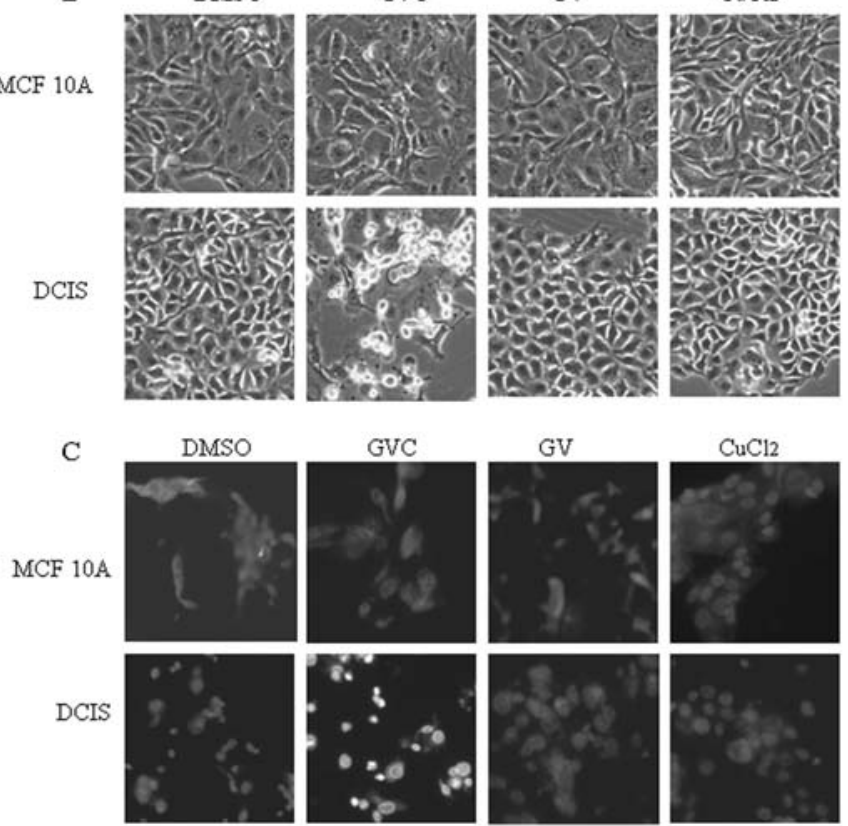

Figure 6. The differential effects of GVC in normal and malignant breast cells. Normal, immortalized human breast MCF $10 \mathrm{~A}$ cells and malignant MCF 10DCIS.com (DCIS) cells were treated with $40 \mu \mathrm{M}$ of GVC, L and $\mathrm{CuCl}_{2}$. or DMSO for $48 \mathrm{~h}$. (A) The inhibition of chymotrypsin-like activity was shown in malignant MCF 10DCIS.com, but not in normal MCF 10A cells treated with GVC. Columns, mean of three experiments; bars, \pm SD. (B) Cellular spherical and detached changes (indicating apoptosis) were observed only in malignant MCF 10DCIS.com, but not in normal MCF 10A cells, after treatment with GVC. (C) Punctuated, granular, and brighter nuclei (apoptotic nuclei) were observed in MCF 10DCIS.com, but not in normal MCF 10A cells, treated with GVC after staining with Hoechst 33258.

been used for decades to treat human cancer. Since cisplatin and many other anticancer agents have no tumor-specific and selective effect and are toxic to normal cells, search for new, novel antineoplastic drugs has been going on. In recent years, the amino acid glutamine has received considerable attention as a potential therapeutic adjuvant since its use could improve postoperative clinical outcomes (17).

Glutamine is the most abundant free amino acid in the body, and the function of glutamine goes beyond that of a simple metabolic fuel or protein precursor as previously assumed. Glutamine is known to play a regulatory role in several cellular processes, such as cell integrity, apoptosis and cell proliferation (16). It has been reported that the increase in susceptibility to infections is due to a decrease in plasma glutamine concentration, and that glutamine supplementation decreased upper respiratory tract infections in athletes (27). Recently studies also showed that glutamine is an apoptotic modulator (28).
To further investigate the molecular mechanism of Lglutamine action, we synthesized GV and its copper complex GVC (Fig. 1), and tested their growth inhibition activity in human breast cancer MDA-MB-231 and leukemic Jurkat T cell. We found that GVC potently inhibited proliferation of human breast cancer MDA-MB-231 cells (Fig. 2). In addition, GVC at $50 \mu \mathrm{M}$ inhibited $\sim 75 \%$ MDA-MB-231 cell proliferation, which was more potent than $\mathrm{GV}$ at the same concentration, while $\mathrm{CuCl}_{2}$ exhibited little inhibitory effects on MDA-MB-231 breast cancer cells (Fig. 2).

We have previously shown that Schiff base copper complex was capable of inhibition of the proteasome in a concentrationand time-dependent manner under in vitro conditions (14). Therefore, we hypothesized that GVC might use the same mechanism against cancer cells. To provide direct evidence for proteasome inhibition by this GVC, we performed a cellfree proteasome activity assay using a purified rabbit $20 \mathrm{~S}$ proteasome. We found that GVC was able to inhibit the chymotrypsin-like activity of a purified rabbit 20S proteasome with potency lower than $\mathrm{CuCl}_{2}$. In contrast, $\mathrm{GV}$ had no effect on a purified rabbit $20 \mathrm{~S}$ proteasome (data no shown).

After we showed that GVC can inhibit the cellular proliferation and purified proteasome chymotrypsin-like activity, we then tested its effect in intact MDA-MB-231 cells and found inhibition of the cellular proteasome in a GVC concentration-dependent manner. Proteasomal inhibition by GVC at 40 and $50 \mu \mathrm{M}$ was confirmed by decreased proteasomal activity (Fig. 3A) and increased levels of ubiquitinated proteins and ubiquitinated form of the proteasome target proteins IкB- $\alpha$ (Fig. 3B). In contrast, both $\mathrm{GV}$ and $\mathrm{CuCl}_{2}$ alone had little or no effect even at the highest concentration $(50 \mu \mathrm{M})$. Taken together, these findings indicate that GVC can directly target the cellular proteasome in breast cancer MDA-MB-231 cells.

It has been previously reported that various proteasome inhibitors potently induce apoptosis (4-7). Therefore, we investigated if GVC can demonstrate similar effect. We found that inhibition of the proteasomal chymotrypsin-like activity by $\mathrm{GVC}$, but not by $\mathrm{GV}$ or $\mathrm{CuCl}_{2}$, induced apoptosis in cultured MDA-MB-231 breast cancer cell line. Induction of apoptosis by GVC has been shown in both dose and kinetic assays. Apoptotic morphologic changes and apoptosis-specific PARP cleavage were observed in MDA-MB-231 cells treated with GVC (Figs. 3 and 4). We also found that GVC had similar effects on human leukemia cells (Fig. 5B and C).

After determining that GVC could inhibit proteasome activity and induce apoptosis in MDA-MB-231 and Jurkat $\mathrm{T}$ cells, we then examined the possibility that GVC could specifically and selectively inhibit proteasome activity and induce apoptosis in breast cancer, but not normal, cells. Indeed, out results showed the GVC is a proteasome inhibitor and an apoptosis inducer selectively in human breast cancer MCF 10DCIS.com cells, but not in normal, immortalized human breast MCF 10A cells (Fig. 6). The mechanism for failure of GVC to inhibit the proteasome activity in normal breast cells is currently under investigation.

Our data presented in this study strongly suggest that an important target for GVC is the tumor cellular proteasome, inhibition of the proteasomal activity by GVC triggers apoptotic cell death, and GVC could specifically and 
selectively inhibit proteasome activity and induce apoptosis in breast cancer, but not normal, cells.

In conclusion we have identified the proteasome as a primary target for GVC in human breast cancer and leukemia cells. This finding is particularly important with implications towards possible development of GVC as a novel anticancer drug.

\section{Acknowledgments}

We thank Dr Di Chen for excellent assistance in some of the experiments and Michael Frezza for critical reading of this manuscript. This research was partially supported by a scholarship from the Chinese Scholarship Council (to Y. Xiao) and the National Cancer Institute grant no. 1R01CA120009 (to Q.P. Dou).

\section{References}

1. Zhang AQ, Wu Y, Lai HWL and Yew DT: Apoptosis. Neuroembryology 3: 47-59, 2004.

2. Norbury CJ and Hickson ID: Cellular responses to DNA damage. Annu Rev Pharmacol Toxicol 41: 367-401, 2001.

3. Green DR and Reed JC: Mitochondria and apoptosis. Science 281: 1309-1312, 1998 .

4. An B, Goldfarb RH, Siman R and Dou QP: Novel dipeptidyl proteasome inhibitors overcome $\mathrm{Bcl}-2$ protective function and selectively accumulate the cyclindependent kinase inhibitor p27 and induce apoptosis in transformed, but not normal, human fibroblasts. Cell Death Differ 5: 1062-1075, 1998.

5. Drexler HC: Activation of the cell death program by inhibition of proteasome function. Proc Natl Acad Sci USA 94: 855-860, 1997.

6. Lopes UG, Erhardt P, Yao R and Cooper GM: p53-dependent induction of apoptosis by proteasome inhibitors. J Biol Chem 272: 12893-12896, 1997.

7. Yang HJ, Chen D, Cui QC, Yuan X and Dou QP: Celastrol, a Triterpene extracted from the Chinese 'Thunder of God Vine', is a potent proteasome inhibitor and suppresses human prostate cancer growth in nude mice. Cancer Res 66: 4758-4765, 2006.

8. Dou QP and Li B: Proteasome inhibitors as potential novel anticancer agents. Drug Resist Update 2: 215-223, 1999.

9. Goldberg AL: Functions of the proteasome: the lysis at the end of the tunnel. Science 268: 522-523, 1995.

10. Seemuller E, Lupas A, Stock D, Lowe J, Huber R and Baumeister W: Proteasome from Thermoplasma acidophilum: a threonine protease. Science 268: 579-582, 1995.

11. Abrams MJ and Murrer BA: Metal compounds in cancer therapy and diagnosis. Science 261: 725-730, 1993.

12. Alderden RA, Hall MD and Hambley TW: The discovery and development of cisplatin. J Chem Educ 83: 728-734, 2006.
13. Chen D, Frezza M, Shakya R, Cui QC, Milacic V, Verani CN and Dou QP: Inhibition of the proteasome activity by Gallium (III) complexes contributes to their anti-prostate tumor effects. Cancer Res 67: 9258-9265, 2007.

14. Adsule S, Barve V, Chen D, Ahmed F, Dou QP, Padhye S and Sarkar FH: Novel Schiff base copper complexes of quinoline-2 carboxaldehyde as proteasome inhibitors in human prostate cancer cells. J Med Chem 49: 7242-7246, 2006.

15. Milacic V, Chen D, Ronconi L, Landis-Piwowar KR, Fregona D and Dou QP: A novel anticancer gold (III) dithiocarbamate compound inhibits the activity of a purified $20 \mathrm{~S}$ proteasome and $26 \mathrm{~S}$ proteasome in human breast cancer cell cultures and xenografts. Cancer Res 66: 10478-10486, 2006.

16. Curl R, Lagranha CJ, Doi SQ, Sellitti DF, Procopio J, PithonCuri TC, Corless M and Newsholme P: Molecular mechanisms of glutamine action. J Cell Physiol 204: 392-401, 2005.

17. Newsholme P: Glutamine metabolism: nutritional and clinical significance. J Nutr 131: 2515-2522, 2001.

18. Corless M, Kiely A, McClenaghan NH, Flatt PR and Newssholme P: Glutamine regulates expression of key transcription factor, signal transduction, metabolic gene, and protein expression in a clonal pancreatic B-cell line. J Endocrinol 190: 719-727, 2006.

19. Snotosh KS, Privadarsini KI and Sainis KB: Free radical scavenging activity of vanillin and o-vanillin using 1,1-diphenyl2-picrylhydrazyl (DPPH) radical. Redox Rep 7: 35-40, 2002.

20. Santner SJ, Dawson PJ, Tait L, et al: Malignant MCF10CA1 cell lines derived from premalignant human breast epithelial MCF10AT cells. Breast Cancer Res Treat 65: 101-110, 2001.

21. An B and Dou QP: Cleavage of retinoblastoma protein during apoptosis: an interleukin 1ß-converting emzyme-like protease as candidate. Cancer Res 56: 438-442, 1996.

22. Landis-Piwowar KR, Huo CD, Chen D, Milacic V, Shi GQ, Chan TH and Dou QP: A novel prodrug of the green tea polyphenol (-)-epigallocatechin-3-gallate as a potential anticancer agent. Cancer Res 67: 4303-4310, 2007.

23. Daniel KG, Chen D, Orlu S, Cui QC, Miller FR and Dou QP Clioquinol and pyrrolidine dithiocarbamate complex with copper to form proteasome inhibitors and apoptosis inducers in human breast cancer cells. Breast Cancer Res 7: 897-908, 2005.

24. Chen D, Chen MS, Cui QC, Yang H and Dou QP: Structureproteasome-inhibitory activity relationships of dietary flavonoids in human cancer cells. Front Biosci 12: 1935-1945, 2007.

25. Nam S, Smith DM and Dou QP: Ester bond-containing tea polyphenols potently inhibit proteasome activity in vitro and in vivo. J Biol Chem 16: 13322-13330, 2001.

26. Chen D, Daniel KG, Chen MS, Kuhn DJ, Landis-Piwowar KR and Dou QP: Dietary flavonoids as proteasome inhibitors and apoptosis inducers in human leukemia cells. Biochem Pharmacol 69: 1421-1432, 2005.

27. Nieman DC: Immune response to heavy exertion. J Appl Physiol 82: 1385-1394, 1997.

28. Fuchs BC and Bode BP: Stressing out over survival: glutamine as an apoptotic modulator. J Surg Res 131: 26-40, 2006. 